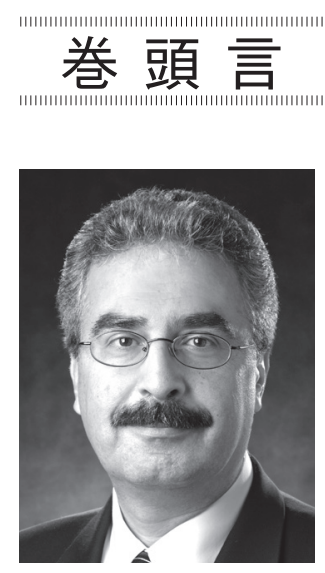

\title{
An Evolving Challenge for the Radiation Protection Community
}

\author{
Armin ANSARI*1
}

Dear friends and colleagues,

I appreciate the opportunity to write this editorial for the Japanese Journal of Health Physics. This is an honor, and I thank you for the opportunity. I would like to start by congratulating you on Japan's successful bid to host the 2020 Summer Olympics! In 1964, Tokyo made history by becoming the first city to host the Olympics in Asia, and it will now become the first city in Asia to host it twice. The Olympics tradition is more than just sports competition and medals; it is a joyous occasion that brings together people of all nations and serves as a festive focal point all around the globe. Unfortunately, such happy global occasions are too infrequent. Usually, it is a major tragic event that brings humanity together on a scale incomparable to any other. The Great East Japan Earthquake was such an event. The whole world was shocked by the magnitude of the tragedy and was awed by the heroism of the Japanese responders and the exceptional spirit of the Japanese nation.

As our Japanese radiation protection colleagues continue to face and meet challenges in the aftermath of disaster at the Fukushima Daiichi nuclear power plant, the international radiation protection community continues to learn from you and your experience. Some time ago, I had the opportunity to review a report that was prepared by the Japan Health Physics Society (JHPS), titled "Issues Associated with Radiation Protection after Fukushima Daiichi Nuclear Power Plant Disaster." *2 The first important issue discussed in the JHPS report was "Strategies for reducing anxiety and doubts of the general public regarding radiation risk." This issue was described as a comprehensive issue related to all situations. I couldn't agree more with that assessment.

We are now approaching the third anniversary of the Great East Japan Earthquake. The struggle of the displaced Japanese population trying to rebuild their livelihood after the tsunami and return to their homes is no longer front page news. However, the leakage of contaminated water from the crippled nuclear power plant makes the news around the globe, and there is concern about potential for contaminated fish entering commerce, even thousands of miles away from the coast of Japan.

Time and again, we find that effective risk communication with the public is the most crucial and challenging aspect of response to any radiation exposure situation. In the critical period immediately following the accident, JHPS set an excellent example and provided valuable service by disseminating information to the public and answering their questions. In a recent editorial, Dr. Roger COATES, elaborated on the importance of explaining and discussing the system of radiation protection with stakeholders and the public, and the crucial role of radiation protection practitioners and non-governmental professional societies such as JHPS. ${ }^{* 3}$ A recent report by the International Atomic Energy Agency also highlighted the importance of communication with the public in an emergency. $^{* 4}$ 
In a given radiological exposure situation, people want to know if they and their families are safe. If not, they want to know what they should do to be safe. We must be able to address this basic need for information effectively. However, the radiation protection community, as a whole, continues to struggle with the concept of "safe." Our terminology and the language we use as scientists, which accommodate an inherent uncertainty in our risk assessments, usually lead to messages that may come across as vague, uncertain, and ultimately not as effective.

One factor that transcends all others in how the public evaluates the information they receive is TRUST. Does the public trust that the authorities are competent, open, honest, and most important of all, empathetic? If public trust is lacking or eroded for whatever reason, it is very difficult to regain it. And unless the trust deficit is overcome, communication strategies are seldom as effective as they would be otherwise.

As a community of radiation protection professionals, our approach to public communication and messaging has changed a great deal over the past few decades. This is a continuously evolving challenge. There will always be generational and cultural changes in people's expectations and the way people receive and perceive information. We must keep pace, and continue to critically evaluate our own protection systems, terminology, and methods of communication, to make sure they meet our evolving needs. Above all, we must always try hard to maintain the public trust in our profession and in our professional organizations.

\section{Armin ANSARI}

Armin Ansari, PhD, CHP is the immediate Past President of the U. S. Health Physics Society. Dr. Ansari has 30 years of experience and a broad range of expertise gained from working in academic research, environmental consulting, and emergency preparedness and response arenas. He earned both his $\mathrm{BS}$ and $\mathrm{PhD}$ degrees in radiation biophysics from the University of Kansas, starting his career as a radiation biologist, and did his postdoctoral research on molecular mechanisms of radiation-induced mutagenesis at Oak Ridge and Los Alamos National Laboratories. He is currently with the U. S. Centers for Disease Control and Prevention and serves as subject matter expert in radiation emergency preparedness. He served on a Homeland Security Council interagency committee for preparedness and response to radiological and nuclear threats, and was a contributing author to the federal Planning Guidance for Response to a Nuclear Detonation. Dr. ANSARI is also an adjunct associate professor of nuclear and radiological engineering at Georgia Institute of Technology, and author of the textbook Radiation Threats and Your Safety: A Guide to Preparation and Response for Professionals and Community. He works closely with local and state agencies on matters related to nuclear and radiological emergency preparedness, conducts training workshops, and lectures extensively on this topic to technical and non-technical audiences.

*1 Past-President of the U.S. Health Physics Society, 1313 Dolley Madison Blvd., Suite 402, McLean, VA 22101.

*2 This report is available from the JHPS web site: www.jhps.or.jp/en/.

*3 Coates, R. The Future of Radiation Protection after the Fukushima Accident - an IRPA Perspective, Jpn. J. Health Phys., 47, 161-162 (2012).

*4 International Atomic Energy Agency (IAEA) Report on Preparedness and Response for a Nuclear or Radiological Emergency in the Light of the Accident at the Fukushima Daiichi Nuclear Power Plant, September 2013, available from http://www.iaea.org/newscenter/focus/ actionplan/reports/preparedness0913.pdf 